Salazar, R., Rybkowski, Z., and Ballard, G. (2017). “An Exploration of Compatibility of U.S. Army Culture and Lean Construction" In: LC3 2017 Volume II - Proceedings of the 25th Annual Conference of the International Group for Lean Construction (IGLC), Walsh, K., Sacks, R., Brilakis, I. (eds.), Heraklion, Greece, pp. 413-420. DOI: https://10.24928/2017/0199.

\title{
AN EXPLORATION OF COMPATIBILITY OF U.S. ARMY CULTURE AND LEAN CONSTRUCTION
}

\author{
Ralph T. Salazar, ${ }^{1}$ Zofia K. Rybkowski ${ }^{2}$ and Glenn Ballard ${ }^{3}$
}

\begin{abstract}
The culture of the United States Army has evolved significantly over the course of the service of the present generation of Soldiers. Through the implementation of Lean Management practices, and Six Sigma measurement and analysis tools, Army leaders are more able to competently perform a mission or accomplish a business goal. Through careful case study of previous missions, effort spent building learning organizations, and cultivating a culture of respect, leaders have discovered a formula to optimize unit performance. The keys to unlocking the benefits of Lean's historically proven efficiency methods lie in changing the attitude and mindset of the Army's workforce to effectively apply lean methods to the myriad projects and tasks that the citizens of the United States ask its Soldiers to perform every day. Cultural transformation must occur, however, in an unforgiving environment that poses significant threats to our national security, leaving very little margin for error in applying the new managerial methodology to both state-side and war-side operations. Using as its framework Jeffrey Liker's Principles of Management described in The Toyota Way, this paper will explore the ways in which the U.S. Army is already equipped to implement lean, and those areas where more cultural evolution must take place to take full advantage of the philosophy. Viewing the Army culture as a whole, and then discussing more specifically Health Facility Development and Military Hospital Construction, the authors' contention is that the U.S. Army and Lean Construction are more compatible than may appear at first glance.
\end{abstract}

Keywords: Lean Construction, Military Culture, Military Decision Making

\section{INTRODUCTION}

The United States armed forces have been engaged in a protracted conflict for over 15 years. This state of high operational tempo has eroded the readiness, capability, and, in some cases, the productivity of the force over the last decade. The negative effects on a war-weary workforce may be evident, due in part to a pernicious cycle of executing a wartime mission followed by stateside reset and recovery. It was on the home-front that this degradation became most apparent. In response to the decline in the efficiency of the Department of Defense, strategists at the Pentagon's Office of the Deputy Chief of Staff Business Transformation Division began searching for solutions to the dwindling productivity. On May 15, 2008 the Department of Defense (DoD) issued Directive number 5010.42. This directive served as a mandate to all DoD branches to establish a Continuous Process Improvement (CPI) and Lean Six Sigma (LSS) program which was to be the primary means to assess and continually improve the effectiveness and efficiency of DoD processes. The program's

\footnotetext{
${ }^{1}$ Graduate Student, Department of Construction Science, College of Architecture, Texas A\&M University, College Station, Texas, 77843-3137 USA, ralph.salazar@tamu.edu (corresponding author)

${ }^{2}$ Associate Professor, Department of Construction Science, College of Architecture, Texas A\&M University, College Station, Texas, USA, 77843-3137, Ph :+1-979-845-4354, zrybkowski@tamu.edu

${ }^{3}$ Research Director, Project Production Systems Laboratory, Civil and Environmental Engineering Dept., University of California, Berkeley, 407 McLaughlin Hall, CA94720-1712, USA, ballard@ce.berkeley.edu
} 
initiative was to strengthen the military's capabilities and improve the following lines of effort: Productivity, Performance, Safety, Flexibility and Energy Efficiency (DoD Directive 2008). This mandate would, of course, come with funding to support the educational and implementation requirements of such a program. The rationale was that it sometimes costs money to save money, and ultimately improve the way we do business. In accordance with Jeffrey Liker's (2004) first principle of basing "management decisions on a long-term philosophy, even at the expense of shortterm financial goals," the DoD invested in lean programs (p. 37). CPI/LSS was the vehicle to achieve transformation, in spite of a few inconsistencies in lean philosophy when compared to the military hierarchical structure of making decisions and executing work.

In fulfillment of the requirement, the U.S. Army Medical Command (MEDCOM) began a concerted effort to train and equip its workforce with the knowledge required to implement a CPI/LSS program. Dr. Donna Whittaker, the MEDCOM Lean Six Sigma deployment director, and her colleagues, developed an academic pipeline to produce certified Lean Six Sigma leaders who could apply the waste mitigating and performance measurement techniques learned in the classroom to their respective organizations. Lean operations became the gold standard in U.S. Army Medicine and while many systems were streamlined, and billions of dollars saved, there were still some aspects of the lean philosophy that were incompatible with Army culture (Lopez 2016). As the organization begins to apply lean to more widespread facets of Army Medicine, specifically Health Facility Development and Military Medical Treatment Facility Construction, it will become even more important that we understand the dissimilarities between traditional lean philosophy and current Army culture.

The purpose of this paper is to explore ways in which the military and lean are compatible while striving to understand what cultural adaptations could be made to more effectively implement lean. The idea that parallels can be drawn between lean and military strategy is not new. Low and Teo (2005) suggest that lean production principles may have been influenced by Sun Tzu's Art of War. They did not analyze, however, how U.S. military culture may change the way lean is implemented and enacted. While the United States Army has begun to implement lean operations in the healthcare environment, it has yet to fully implement many of the tools at the disposal of a Lean Construction practitioner while undertaking military health facility development. Several peerreviewed articles in The Military Engineer, the official professional journal of the Society of American Military Engineers, call for an overhaul of military construction delivery methodology. Specifically, Peter Cholakis, in his article "Rethinking Construction Delivery" (2015), contends that "leaner" construction practices and tools such as BIM may be precisely what military constructors need to implement to ensure project success. Lean tools notwithstanding, in order to take full advantage of the methodology, an organization must adapt its culture, as necessary, to embrace a more lean-centric way of thinking. This paper will examine U.S. Army Medicine and, using The Toyota Way (Liker 2004) and Liker's Management Principles, determine which of those principles are already being successfully implemented, while highlighting those that present a greater challenge. Table 1 lists the Toyota Way principles that the U.S. Army has already implemented, or that already existed. 
Table 1: Excerpt from Liker’s 14 Management Principles (Liker 2004)

\begin{tabular}{|c|c|c|c|}
\hline $\begin{array}{l}\text { Principle } \\
\text { Number }\end{array}$ & Content & Military Applicability & $\begin{array}{c}\text { Compatibility } \\
\text { (War-side / State-side })\end{array}$ \\
\hline 1 & Long-Term Philosophy & $\begin{array}{c}\text { Decision to invest in Lean } \\
\text { Six Sigma }\end{array}$ & Low / High \\
\hline 13 & $\begin{array}{l}\text { Make decisions slowly by } \\
\text { consensus, execute rapidly }\end{array}$ & $\begin{array}{l}\text { Army post-war leadership } \\
\text { transformation initiative }\end{array}$ & Medium / Medium \\
\hline 9 & $\begin{array}{c}\text { Grow Leaders with thorough } \\
\text { understanding of the } \\
\text { philosophy }\end{array}$ & $\begin{array}{l}\text { Formal pipeline to train lean } \\
\text { practitioners }\end{array}$ & Low / Medium \\
\hline 10 & $\begin{array}{l}\text { Develop exceptional people } \\
\text { and teams }\end{array}$ & $\begin{array}{l}\text { Professional Military } \\
\text { Education focuses on } \\
\text { developing people }\end{array}$ & High / High \\
\hline 14 & $\begin{array}{l}\text { Become a learning } \\
\text { organization }\end{array}$ & $\begin{array}{l}\text { Assess current state and } \\
\text { evolve to world class } \\
\text { (healthcare) }\end{array}$ & Medium / High \\
\hline 5 & Stop to Fix Problems & $\begin{array}{l}\text { High Reliability } \\
\text { Organization }\end{array}$ & High / High \\
\hline 6 & $\begin{array}{c}\text { Standardize Tasks / } \\
\text { Continuous Improvement }\end{array}$ & $\begin{array}{l}\text { Standard Operating } \\
\text { Procedures }\end{array}$ & High / Medium \\
\hline
\end{tabular}

In this exploration, only the principles that focus on the collaborative aspects of lean will be addressed (i.e. those shown in Table 1). Those principles that are more operationally oriented (i.e. process flow) and do not deal with building consensus or making decisions are outside the scope of this paper and represent areas for further exploration.

\section{THE EVOLUTION OF LEAN IN THE U.S. ARMY}

\subsection{Managing Change}

The dichotomy of grooming leaders to give orders in a deployed or wartime environment compared to the way that same leader is asked to build consensus and make decisions in a state-side or peacetime environment is striking. There is a time and place for consensus building, but the middle of a kinetic and tactical environment, where the stakes are life or death, is not necessarily one of them. An entire generation of warfighters has been baptized in the crucible of combat, in some cases leading to a rigid and inflexible hierarchy resistant to soliciting ideas or innovation from its subordinates. This is sometimes necessary in a combat environment, but it can be detrimental to an organization in a stateside business environment. In 2006, when General David Petraeus penned the U.S. Army Counterinsurgency Field Manual 3-24, he recognized then that even in tactical situations, soliciting bottom-up refinement can be a healthy, team building event (FM 3-24 2006). He wrote:

Open channels of discussion and debate are needed to encourage growth of a learning environment in which experience is rapidly shared and lessons adapted for new challenges. The speed with which leaders adapt the organization must outpace 
insurgents' efforts to identify and exploit weaknesses or develop countermeasures. (p. 7-9)

This concept is in line with Liker's $13^{\text {th }}$ Principle of "making decisions slowly by consensus, thoroughly considering all options, and implementing decisions rapidly" (Liker 2004). "Speed" is a relative thing in a warzone, but the premise is that if appropriate time is taken to discuss decisions with the team, trust is built. With buy-in and trust built through consensus, a leader will more aptly be able to manage his or her team. The same is true of decisions in Health Facility Development while conducting peacetime operations. Rather than decisions being made solely "at the top," design and construction professionals should develop a network of decision- makers to collectively agree on design interventions in military hospitals. One of the organizational challenges that the U.S. Army has to overcome is that units (hospital organizations) experience fairly rapid turnover. On average, Commanders ${ }^{4}$ change command every two years, which often results in a changing of the guard in the middle of enduring 4-5 year megaprojects. Health Facility Developers who build a network of decision makers may preclude some of the issues that arise when a new Hospital Facility Commander takes command shortly before the commissioning of a new hospital. There are occasions when the new commander decides to make sweeping changes to the design resulting in significant delays and cost over-runs due to change-orders and rework. When a design decision rests with "the team," it is much harder for the "new Boss" to overturn it. With the implementation of Lean Six Sigma, organizations are having to address the impact of combat on leadership development-and assess with a critical eye-how decisions are made. This is a healthy exercise for an organization that is transforming to a more lean and agile institution.

\subsection{Building the Bench}

The U.S. Army Training and Doctrine Command (TRADOC) has a large role to play in the lean transformation as well. This major command is responsible for "training the force," and manages all of the professional military education courses in the U.S. Army. In these courses, student Soldiers learn through experiential case study, and evolve as men and women who understand servant leadership. Hard conversations are engaged in about the types of leaders whom they have served, and the leader that they have become, or wish to become. Understanding culture is the foundation of the advanced courses, and white papers are studied relative to what it means to be in the Profession of Arms (TRADOC 2010).

In these environments, rank is metaphorically removed, and honest assessments about the state of the organization are given. This is a crucial step in evolving as a lean organization. Leaders must be willing to accept-and even celebrate-failure in an effort to truly understand why a specific mission or business initiative did not go as planned. For more than a decade, the U.S. Army has embarked on this journey, only to battle a silent resistance to flattening the hierarchy. Brilliant men and women who spent entire careers watching this evolution also acknowledge the need for change. General Peter Chiarelli, the 32nd Vice Chief of Staff of the U.S. Army who served in that capacity from August, 2008 to January, 2012, made the following inference in his article on Modern Wars, implying inherent issues with current Army culture:

The military must continually look at ways to flatten their organizational structures... increase opportunities-and rewards-for leaders to serve in assignments outside the traditional military structure...and then retain only those

\footnotetext{
${ }^{4}$ It is standard practice in Army prose to capitalize rank titles even when used as common nouns (e.g. Commander, Soldier) as a sign of respect.
} 
Americans who have the potential to succeed in tomorrow's complex operating environments... they must ensure all views are welcomed to the debate and that junior leaders have no fear of career retribution for freely stating their opinions. (Chiarelli and Smith 2007, p. 41)

The U.S. Army Field Manual 101-5 Chapter 5: "The Military Decision Making Process" (MDMP), which is taught extensively at TRADOC schools, describes in detail, the art and the science of decision making (MDMP 1997). It delineates between those things that can be operationally measured (the science), while acknowledging that there are other complex and intangible aspects of decision making that are simply more subjective (the art), and rely on the decision-maker having the experience, institutional knowledge, and leadership capability to execute the task. The challenge for many army leaders is taking a system (MDMP) designed to function in a tactical, or combat, environment, and adapting it to a stateside mission. It is in this construct that CPI/LSS excels at bridging the gap, and enables teams to do the analysis necessary to build multiple courses of action to accomplish both business goals and combat missions. Lean, and its philosophy of Continuous Improvement, champions the notion of measuring the state of where you are today, so that you can assess where you want to be tomorrow, and have the tools to implement the plan to get there. Moreover, it does so by advocating a culture of cooperation and shared reward without sub-optimization between the various components of the organization. This is one aspect of lean at which the U.S. Army excels. The Army mantra of "One Team, One Fight" is the phrase that best describes the willingness to selflessly operate in concert with sister units to accomplish a common goal, regardless of who is ultimately left paying the bill. In this regard, the U.S. Army is already well on its way to achieving Liker's $9^{\text {th }}$ and $10^{\text {th }}$ principles of "growing leaders who thoroughly understand the work, and live the philosophy," while "developing exceptional people and teams who follow your company's philosophy" (Liker 2004).

\subsection{Climbing the Kaizen Stairway}

Another aspect of U.S. Army culture that is congruent with Liker's $14^{\text {th }}$ Principle of "becoming a learning organization through relentless reflection (hansei) and continuous improvement (kaizen)" is the Army's steadfast adherence to the practice of conducting After Action Reviews (AAR). The tenets of conducting an AAR are simple. There are four questions asked in every discussion (TC 25-20 1993):

1. What did we set out to accomplish? (Identify the objectives of the mission)

2. What actually happened? (Assess each phase of the mission)

3. Why did it happen? (Without placing blame, assess what went well, and what failed during the mission)

4. What are we going to do next time? (Identify what will change/remain the same in the planning phases and process execution for the next mission)

The AAR is conducted per the guidance in U.S. Army Training Circular 25-20: “A Leader's Guide to After Action Reviews," by an objective third party, not one of the first-line leaders who lead the mission (TC 25-20 1993). Additionally, feedback from the group begins with the lower ranking members first to prevent their opinions and observations from being overshadowed by more senior ranking Soldiers. A comprehensive list of "sustains" and "improves" for each phase are generated, and subsequently drafted into an executive summary for each mission conducted. In rare cases (if mission execution was particularly poor), the facilitator may conduct separate sensing sessions with the different rank structures independently of one another. This autonomy to critically examine the successes and failures of a mission is key to developing a cohesive unit where 
everyone, from the lowest ranking to the highest, feels like his or her vote matters. This empowerment to shape operations is also important in establishing a sense of "ownership" in the organization through team endorsed, command level decisions. The role of the Executive Director (Commander) is to then ensure that the next mission adheres to the best practices of the AARs that were generated by the team. Reading previous executive summaries of similar missions should be the first step a commander and his staff take when planning the current mission. In this way, army units continue to climb the Kaizen Stairway (Rybkowski and Kahler 2014; Seed 2015) and solidify themselves as a "learning organization."

\subsection{Becoming a High Reliability Organization}

Simply cataloging successes and failures through the AAR process is not enough to become great. An organization must go further if it hopes to establish a climate where all employees truly feel empowered to make "on-the-spot" corrections of deficiencies, and in some cases halt the mission altogether. This initiative has recently been implemented in the operation of military hospitals under the command of Lieutenant General Patricia Horoho, the $43^{\text {rd }}$ Surgeon General of the U.S. Army and previous Commander of MEDCOM. In an effort to achieve High Reliability Organization (HRO) status, LTG Horoho began breaking down the barriers of rank structure and military hierarchy to reduce errors, and emphasized placing the customer (patient) first. An HRO is defined as an organizational "environment of collective mindfulness in which all workers look for, and report, small problems or unsafe conditions before they pose a substantial risk to the organization, when they are easy to fix" (Weick and Sutcliffe 2007, p. 38).

The Army suggests there are three components to high reliability: continuous improvement, leadership development, and establishing a culture of safety that empowers every member of the organization to make safety decisions (HRO 2014). While testifying to the Senate Committee for Defense Appropriations on the state of Army Medicine in March, 2015, General Horoho said: "A High Reliability Organization is committed to achieving zero preventable harm by successfully limiting the number of errors in an environment where normal accidents can occur due to the risk factors and complexity of the practice" (Horoho 2015, p. 17). Part of the preventable harm solution is also designing military hospitals in such a manner as to assist practitioners and clinicians in this HRO commitment. By "slowing down to get quality right the first time" and designing the ability to "detect problems" into the built environment (jidoka and Liker's 5 th Principle), Army Medicine can achieve its HRO and world class healthcare goals (Liker 2004).

\subsection{Standardization is Key}

The final principle that this paper will discuss is Liker's $6^{\text {th }}$ principle that states that "standardized tasks and processes are the foundation for continuous improvement and employee empowerment" (Liker 2004). This is another strong suit for the military. The natural inclination for a military person is to execute tasks within a set framework of codified conditions and standards. In fact, the U.S. Army has a Standard Operating Procedure (SOP) for virtually everything it does. However, given the relative infancy of some of its lean implementations, those SOPs, in some cases, are still in the process of being written. There is precedent for developing SOPs to capture lean mechanisms within the army culture and its operations. The "Army Standardization Policy" prescribes responsibilities for implementing standardized programs with respect to procedure, organizational operations, and training. The proponent for this policy is the Deputy Chief of Staff for Operations and Plans headquartered at The Pentagon. The Army defines standardization as, "the management principle which fosters the development and sustainment of a high state of proficiency and readiness among Soldiers and units throughout an organization" (AR 34-4 1984). The objectives of 
the policy are to improve the productivity and development of both the individual Soldier, and the team (unit) as a whole. Due to reassignment of individual Soldiers throughout the Army every 2-3 years, it is also imperative that the Army standardize practices to reduce the adverse effects of personnel turbulence. To that end, the Army refines its practices, and ensures that only those methods of practice that are fully vetted for efficacy endure from generation to generation. These "best practices" are captured in both Army policy (Army Regulation or "AR" manuals) and unit SOP manuals. The challenge is to ensure that while standardization serves as an integral part of the way the Army operates, that it does not stifle initiative or innovation. Careful evaluation of the mechanisms for enforcement and current applicability of the standard is routinely scrutinized for relevancy as the mission, and the culture, changes. This is analogous to the concept of climbing the Kaizen Stairway where Rybkowski and Kahler (2014) suggest, "Effective use of collective kaizen and standardization capitalizes on the ability of individuals to innovate, to learn from one another, and to improve their effectiveness, thus helping managers improve time, cost, quality, safety and morale by engaging the employees they already have" (p. 1).

\section{CONCLUSION}

The duality of the stateside institutional army, versus the wartime operational army is a challenging aspect of the business to overcome. As if caught in a Dr. Jekyll and Mr. Hyde scenario, it is as though military organizations have to reinvent themselves each time they deploy to a theatre of combat, and then return to a stateside mission. The application of lean thinking and lean managerial methodology is not necessarily possible in some tactical environments. Furthermore, without a wholesale cultural transformation, it may be challenging for the U.S. Army to ever be a truly lean organization philosophically, rather than merely an organization which happens to implement a few lean techniques. That said, there are many cultural norms in the Army that lend themselves quite well to fitting into the lean organizational framework. In this paper, seven of the fourteen lean principles were addressed, and deemed by the authors and military colleagues to be precisely in line with the attributes Liker says a lean organization should exhibit. A strong argument can be made that the other seven principles are at least partially fulfilled by certain facets of U.S. Army business. Perhaps the current climate promoting budget reduction is conducive to the Army's willingness to implement more lean cost saving measures. As Womack and Jones (1996) wrote, "lean provides a way to do more and more with less and less-less human effort, less equipment, less time, and less space-while coming closer and closer to providing customers with exactly what they want." (p.36) Unfortunately, in the same way that the construction industry has sometimes struggled to develop analogous systems to Toyota's manufacturing processes, so too is the Army challenged with applying all of Liker's lean principles to its varied and diverse mission portfolio. In the end, however, it is well worth the effort to try.

\section{REFERENCES}

Chassin, M.R. and Loeb, J.M. (2013). "High-Reliability Health Care: Getting There from Here," The Milbank Quarterly, 91 (3), 459-490. Chiarelli, P.W. and Smith, S.M. (2007). "Learning from Our Modern Wars: The Imperatives of Preparing for a Dangerous Future," Military Review, September. Cholakis, P. (2015). "Rethinking Construction Delivery," The Military Engineer, July $<$ http://themilitaryengineer.com/index.php/item/492-rethinking-construction-delivery> November 15, 2016. 
Department of Defense Directive. (2008). DoD-Wide Continuous Process Improvement (CPI)/Lean Six Sigma (LSS) Program, DoD Directive No. 5010.42, Washington, DC:

U.S. Gov. Printing Office.

Department of the Army. (1984). Army Standardization Policy (AR 34-4),

Washington, DC: Headquarters, Department of the Army.

Department of the Army. (1993). A Leaders Guide to After-Action Reviews (TC 25-20),

Washington, DC: Headquarters, Department of the Army.

Department of the Army. (1997). The Military Decision Making Process (FM 101-5),

Washington, DC: Headquarters, Department of the Army.

Department of the Army. (2006). Counterinsurgency (FM 3-24), Washington, DC: Author, General David Petraeus.

Department of the Army. (2010). The Profession of Arms (Whitepaper), Released in

Review: Army Profession in an Era of Persistent Conflict. Washington, DC: Headquarters, TRADOC.

High Reliability Organization (2014). <http://armymedicine.mil/Documents/Panel-A-HROPlacemat-AUSA-Medical-Hot-Topics.pdf $>16$ November, 2016.

Liker, J. (2004). "The 14 Principles of The Toyota Way: An Executive Summary of the Culture Behind TPS," <http://www.si.umich.edu/ICOS/Liker04.pdf> Nov. 14, 2016.

Liker, J. (2004). The Toyota Way: 14 Management Principles from the World's Greatest Manufacturer. New York: McGraw-Hill.

Lopez, C.T. (2016). “Army's Lean, Six Sigma practitioners free up \$1.1 billion in 2015” <https://www.army.mil/article/175162/armys_lean_six_sigma_practitioners_free_up_11_ billion_in_2015> November 15, 2016.

Low S. P., and Teo H. F., (2005) "Modern-day lean construction principles: Some questions on their origin and similarities with Sun Tzu's Art of War." Management Decision, 43(4), $523-541$.

Rybkowski, Z. K., and Kahler, D. L. (2014). "Collective kaizen and standardization: the development and testing of a new lean simulation," Proceedings of 22nd Annual Conference of the International Group for Lean Construction. Oslo, Norway, 25-27.

Seed, W. R., ed. (2015). “Ch. 31: Continuous Improvement (Kaizen Stairway)," Transforming Design and Construction: A Framework for Change, Lean Construction Institute, Arlington, VA, 179-185.

Sequestration's effect on Army Medicine: Defense Health Program: Testimony before the Senate Committee on Appropriations: Subcommittee on Defense, 114th Cong., 1 (2015) (testimony of Lieutenant General Patricia D. Horoho, The Surgeon General, US Army).

Weick, K.E. and Sutcliffe, K.M. (2007). Managing the Unexpected, 2nd ed. San Francisco, CA: Jossey-Bass.

Womack, J.P. and Jones, D.T. (1996). Lean Thinking. New York, NY: Simon and Schuster. 